\title{
Risk factors for severe outcome of cases with pandemic influenza $\mathrm{A}(\mathrm{H} 1 \mathrm{~N} 1)$ pdm09
}

\author{
Hlavinkova $\mathrm{L}^{1}$, Kristufkova $\mathrm{Z}^{1}$, Mikas $\mathrm{J}^{2}$ \\ Slovak Medical University, Bratislava, Slovakia. kristufkova@gmail.com
}

\begin{abstract}
OBJECTIVES: The aim of this study is to describe demographic, clinical and epidemiological characteristics of cases with laboratory-confirmed pandemic influenza virus A(H1N1)pdm09 reported in Slovakia from May 28, 2009 to December 30, 2009 and analyse the association between risk factors and severe outcome of these cases. BACKGROUND: In the spring of 2009, an outbreak of a pandemic influenza virus A(H1N1)pdm09, emerged in Mexico and spread globally. Until December 2009, 1,014 cases were notified in Slovakia.

METHODS: The data were collected within national influenza surveillance system. Odds ratios $(95 \% \mathrm{Cl})$ were calculated. Associations were found to be significantly associated with the worse outcome $(p<0.05)$ in the univariate analysis and were adjusted for possible effects of age and sex by using a logistic regression model. RESULTS: Out of the total number of 1,014 cases, $131(12.9 \%)$ cases were hospitalized, and $43(4.2 \%)$ of those were admitted to intensive care units. During the reporting period, 38 deaths were reported, representing a case fatality rate of $3.75 \%$. The median age of severe cases (35 years, IQR $=29$ y) was significantly higher than the median age of mild cases (24 years, IQR = $19 \mathrm{y} ; \mathrm{p}<0.001)$. By using a logistic regression, we found out that chronic obstructive pulmonary disease (COPD) (aOR $=9.2 ; 95 \% \mathrm{Cl}$ : 1.42-59.98), cardiovascular diseases (aOR $=14.97 ; 95 \% \mathrm{Cl}: 5.49-40.79)$, malignity $(\mathrm{aOR}=7.6 ; 95 \% \mathrm{Cl}: 1.95-29.37)$ and gravidity $(\mathrm{aOR}=$ $55.21 ; 95 \% \mathrm{Cl}: 14.40-211.58)$ were significantly associated with severe outcomes of the cases.

CONCLUSION: The fact, that $35 \%$ of severely ill patients did not report any risk factor suggests the importance of vaccination as a prevention of influenza (Tab. 2, Fig. 1, Ref. 18). Text in PDF www.elis.sk. KEY WORDS: pandemic influenza $A(\mathrm{H} 1 \mathrm{~N} 1)$ pdm09, risk factor, severe outcome of the disease.
\end{abstract}

\section{Introduction}

In the spring of 2009, an outbreak of respiratory disease caused by a new type of influenza virus, later identified as a pandemic influenza virus $\mathrm{A}(\mathrm{H} 1 \mathrm{~N} 1) \mathrm{pdm} 09$, emerged in Mexico and spread globally (1). On April 25, 2009, the World Health Organization (WHO) recognized the outbreak as a public health emergency of international concern under the International Health Regulation (2). On June 11, 2009 WHO director-general raised the level of influenza pandemic alert to the phase 6 (3).

After the alert of WHO and European Centre for Disease Prevention and Control (ECDC) at the end of April 2009, Slovakia intensified The National Influenza Surveillance System in order to detect first cases (4), which happened on May 25, 2009 (4). During the early phase of the pandemic, Slovakia, as other European countries, reported daily case-based and aggregated data to ECDC through the Early Warning and Response System (EWRS). After the week $39 / 2009$, Slovakia reported data weekly and in a new format. Since November 2009, a hospital sentinel surveillance of severe acute respiratory infection (SARI) was established (4).

${ }^{1}$ Slovak Medical University, Bratislava, Slovakia, and ${ }^{2}$ Public Health Authority of the Slovak Republic, Bratislava, Slovakia

Address for correspondence: $\mathrm{Z}$. Kristufkova, MD, PhD, MPH, Slovak Medical University, Limbova 12, SK-833 03 Bratislava, Slovakia. Phone: +421.903354404
The need for new research on pandemic influenza has been recently declared (5).

In this article we describe demographic characteristics, clinical symptoms and risk factors for severe outcome of cases with laboratory-confirmed pandemic influenza virus A(H1N1)pdm09 reported in Slovakia between May 28, 2009 and December 30, 2009 and analyze the association between risk factors and severe outcome of the cases.

\section{Methods}

\section{Inclusion criteria}

Eligible cases included adults and children with clinical symptoms of influenza with laboratory-confirmed pandemic influenza virus $\mathrm{A}(\mathrm{H} 1 \mathrm{N1}$ )pdm09 reported in Slovakia from May 28, 2009 to December 30, 2009. The laboratory confirmation method was based on reverse transcription polymerase chain reaction (RTPCR) or real-time reverse transcription polymerase chain reaction (rRT-PCR).

Risk factor for severe outcome was defined as allergy, any pulmonary disease, asthma, COPD, cardiovascular disease, malignity, neuromuscular disease, diabetes mellitus, chronic renal insufficiency, chronic hepatic disease, obesity (BMI 30-40), gravidity, immunodeficiency (except HIV), HIV, leucopenia and hematuria. 


\section{9-393}

The outcome of case was defined as severe when symptoms of influenza with laboratory-confirmed pandemic influenza virus $\mathrm{A}(\mathrm{H} 1 \mathrm{~N} 1) \mathrm{pdm} 09$ required hospitalization at intensive care unit (i.e. ICU) and/or the patient developed pneumonia and/or died.

\section{Data collection}

The data on pandemic influenza cases were reported in two ways. Local epidemiologists reported the cases to the Department of Epidemiology at Public Health Authority of the Slovak Republic (PHA SR) by phone or e-mail and they simultaneously entered those cases into the Epidemiological Information System. The following data were collected: demographic data, clinical characteristics, underlying risk conditions for severe outcome, treatment, outcome of illness, and vaccination status.

Two databases were merged based on personal identificators (identification number or birth date and name).

\section{Analysis}

The data analyses were performed by using STATA 10.5 .

Odds ratios with $95 \%$ confidence intervals were used as the measure of association between risk factor and outcome of illness (severe vs. non-severe outcome).

Associations were found to be significantly associated with the worse outcome $(\mathrm{p}<0.05)$ in the univariate analysis and were adjusted for possible effects of age and sex by using a logistic regression model

\section{Results}

From May 28, 2009 to December 30, 2009, a total number of 1,014 cases were notified to the PHA SR, leading to a cumulative

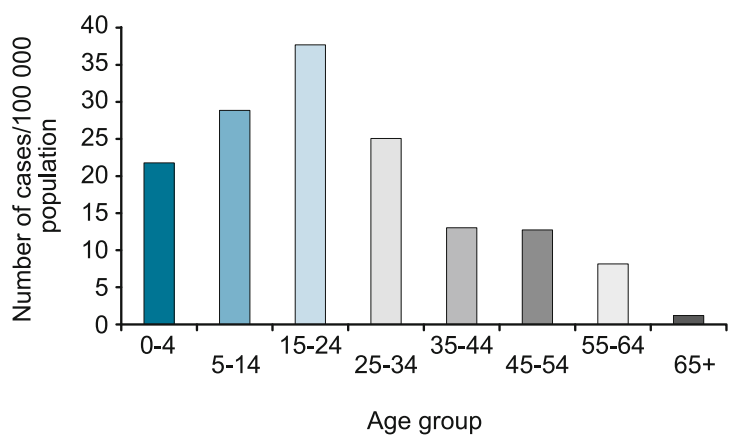

Fig. 1. Age-specific incidence of cases with laboratory-confirmed virus of pandemic influenza. *Data on age were missing in $\mathbf{3}$ cases.

incidence of 18.7 per 100,000 population. Of 1,014 cases, 131 $(12.9 \%)$ were hospitalized, of which 43 (4.2\%) required admission to intensive care unit (ICU). Thirty-eight cases died (incidence: 0.7/100,000 population; case-fatality rate: $3.75 \%$ ).

\section{Demographic characteristics}

The median age of cases was 25 years (range: $0-89$ years). The most affected age group was 15-24 years with the number of cases 297 (29.3\%; 37.7/100,000 population). The least affected were cases aged 65 years or older with the number of cases $8(0.8 \%$; 1.2/100 000 population) (Fig. 1).

The median age of deceased cases was 36 years (range: 0-66 years). The highest number of cases died in the age group of $45-54$ years with the number of cases $9(23.7 \% ; 1.2 / 100,000$ population). The lowest number of cases died in the age group

Tab. 1. Risk factors of cases with laboratory-confirmed virus of pandemic influenza A(H1N1)pdm09 in Slovakia by outcome, 2009 (n =1014).

\begin{tabular}{|c|c|c|c|c|c|}
\hline \multirow{2}{*}{ Risk Factor (RF) } & Severe Outcome $n=57$ & Non-severe Outcome $n=957$ & & & \\
\hline & $\mathrm{n}^{\mathrm{a}} / \mathrm{N}^{\mathrm{b}}(\%)$ & $\mathrm{n} / \mathrm{N}^{\mathrm{b}}(\%)$ & Adjusted OR & $95 \% \mathrm{CI}$ & $\mathrm{p}$ value \\
\hline \multicolumn{6}{|l|}{ Demographic characteristics } \\
\hline Median age & 35 & 24 & 1.03 & $1.01-1.04$ & 0.010 \\
\hline Female & $30 / 57(52.63)$ & $485 / 957(50.68)$ & - & - & - \\
\hline \multicolumn{6}{|l|}{ Underlying conditions } \\
\hline Pulmonary disease & $9 / 57(15.79)$ & $26 / 957(2.71)$ & 2.44 & $0.64-9.37$ & 0.194 \\
\hline Asthma & $1 / 57(3.51)$ & $21 / 957(2.30)$ & - & - & - \\
\hline Cardiovascular disease & $11 / 57(19.30)$ & $10 / 957(1.04)$ & 14.97 & $5.49-40.79$ & 0.000 \\
\hline Malignity & $4 / 57(7.27)$ & $9 / 957(0.94)$ & 7.58 & $1.95-29.37$ & 0.003 \\
\hline Neuromuscular disease & $1 / 57(1.75)$ & $8 / 957(0.84)$ & - & - & - \\
\hline Diabetes mellitus & $4 / 57(7.02)$ & $5 / 957(0.52)$ & 5.35 & $0.91-31.31$ & 0.063 \\
\hline Chronic renal insufficiency & $2 / 57(3.51)$ & $5 / 957(0.52)$ & - & - & - \\
\hline Chronic hepatic disease & $1 / 57(1.75)$ & $3 / 957(0.31)$ & - & - & - \\
\hline Obesity (BMI 30-40) & $3 / 51(5.88)$ & $1 / 38(2.63)$ & - & - & - \\
\hline Allergy & $0 / 7(0.00)$ & $16 / 288(5.56)$ & - & - & - \\
\hline Immunodeficiency (except HIV) & $0 / 7(0.00)$ & $4 / 288(1.39)$ & - & - & - \\
\hline HIV & $0 / 7(0.00)$ & $1 / 288(0.35)$ & - & - & - \\
\hline Leucopenia & $0 / 7(0.00)$ & $1 / 288(0.35)$ & - & - & - \\
\hline Hematuria & $0 / 7(0.00)$ & $1 / 288(0.35)$ & - & - & - \\
\hline
\end{tabular}

a Number of cases with particular characteristic

${ }^{\mathrm{b}}$ Number of cases with data available

${ }^{\mathrm{C}}$ Chronic obstructive pulmonary disease

${ }^{d}$ Number of women of childbearing age (i.e. 15-44 years) as denominator 
Tab. 2. Number of risk factors of cases with laboratory-confirmed virus of pandemic influenza A(H1N1)pdm09 in Slovakia by outcome, 2009 $(\mathbf{n}=1014)$.

\begin{tabular}{|c|c|c|c|c|c|}
\hline \multirow{2}{*}{ Number of Risk Factors (RF) } & Severe Outcome $n=57$ & Non-severe Outcome $n=957$ & & & \\
\hline & $\mathrm{n} / \mathrm{N}(\%)$ & $\mathrm{n} / \mathrm{N}(\%)$ & Adjusted OR & $95 \% \mathrm{CI}$ & $\mathrm{p}$ value \\
\hline $0 \mathrm{RF}$ & $20 / 57(35.09)$ & $859 / 957(90.51)$ & 0.08 & $0.04-0.15$ & 0.000 \\
\hline $1 \mathrm{RF}$ & $30 / 57(52.63)$ & $92 / 957(8.86)$ & 3.28 & $1.01-10.66$ & 0.048 \\
\hline 2 and more RFs & $7 / 57(12.28)$ & $6 / 957(0.63)$ & 8.58 & $4.80-15.32$ & 0.000 \\
\hline
\end{tabular}

of 65 years or older with 1 deceased case $(2.6 \% ; 0.2 / 100000$ population).

Male-to-female ratio was 1.03:1. Out of 515 women, 322 were of childbearing age and 12 of them $(3.73 \%)$ were pregnant.

\section{Clinical characteristics}

Data on clinical characteristics were available in $382(37.7 \%)$ cases. The most common symptoms included fever ( $n=324 ; 84.8 \%$ ) and acute respiratory symptoms such as cough, sore throat, coryza $(\mathrm{n}=322 ; 84.3 \%)$, followed by headache $(\mathrm{n}=161 ; 42.1 \%)$, myalgia $(\mathrm{n}=160 ; 41.9 \%)$ and arthralgia $(\mathrm{n}=135 ; 35.3 \%)$. Shortness of breath was reported in $47(12.3 \%)$ cases, and fatigue in $39(10.2 \%)$ cases. Gastrointestinal symptoms were observed in 37 (9.7\%) cases.

\section{Underlying conditions}

The most common underlying conditions of the cases included allergy 19/295(5.4\%), obesity 4/89(4.5\%), gravidity $12 / 322(3.7 \%)$, pulmonary disease $35 / 1,014(3.5 \%)$, asthma $22 / 1,014(2.2 \%)$, cardiovascular disease 21/1,014 (2.1\%), immunodeficiency except HIV 4/295 (1.4\%), malignity 13/1014 (1.3\%), COPD 11/1,014 $(1.1 \%)$, neuromuscular disease $9 / 1,014(0.9 \%)$, diabetes mellitus 9/1,014 (0.9\%) Seven patients had chronic renal insufficiency $(0.7$ $\%$ ) and four patients had chronic hepatic disease (0.4\%). Other underlying conditions were in single cases, namely HIV, leucopenia and hematuria.

\section{Association of risk factors with severe outcome}

Among the total number of 1,014 cases included in our study, $57(5.6 \%)$ cases had a severe outcome. Forty-three cases were admitted to ICU (20 cases had pneumonia and died; 4 cases had pneumonia and survived; 9 cases died from reasons other than pneumonia; 10 cases were admitted to ICU for reasons other than pneumonia and survived); 14 cases were admitted to departments other than ICU ( 5 cases had pneumonia and survived; 9 cases died from reasons other than pneumonia).

None of the 57 cases with severe outcome were vaccinated against seasonal influenza. Vaccination against pandemic influenza was not yet available at that time in Slovakia.

We conducted a multivariate analysis with the risk factors, which were significant in the univariate analysis: any pulmonary disease, COPD, cardiovascular disease, malignity, diabetes mellitus, and gravidity. Chronic obstructive pulmonary disease (COPD), cardiovascular disease, malignity and gravidity were independently associated with the severe outcome. Study patients with severe outcome were 9.16-fold (95\% CI: 1.42-59.98, $\mathrm{p}=0.020$ ) more likely to have a COPD, 14.97 -fold ( $95 \%$ CI: $5.49-40.79, \mathrm{p}$ $=0.000$ ) more likely to have a cardiovascular disease, 7.58 -fold
(95\% CI: $1.95-29.37, \mathrm{p}=0.003)$ more likely to have a malignity and 22.17 -fold (95\% CI: 4.36-112.64, $\mathrm{p}=0.000)$ more likely to be pregnant than study patients with non-severe outcome.

There was no association found between pulmonary disease, asthma, neuromuscular disease, diabetes mellitus, chronic renal insufficiency, chronic hepatic disease, obesity, allergy, and immunodeficiency except HIV, HIV, leucopenia, hematuria and severe outcome (Tab. 1).

After adjusting for age and sex, the absence of risk factors seems to have a protective effect on the disease severity $(\mathrm{aOR}=$ $0.08,95 \%$ CI: $0.04-0.15, \mathrm{p}=0.000)$. Study patients with severe outcome were 3.28-fold (95\% CI: $1.01-10.66, \mathrm{p}=0.048)$ more likely to have 1 risk factor and 8.58 -fold (95\% CI: 4.80-15.32, p $=0.000$ ) more likely to have 2 and more risk factors compared to study patients with non-severe outcome (Tab. 2).

\section{Discussion}

This study describes demographic, clinical and epidemiological characteristics of cases with laboratory-confirmed pandemic influenza virus $\mathrm{A}(\mathrm{H} 1 \mathrm{~N} 1) \mathrm{pdm} 09$ reported in Slovakia from May 28, 2009 to December 30, 2009, and analyses the association between risk factors and severe outcome of these cases.

During the study period, a total number of 1,014 cases were notified to PHA SR, leading to a cumulative incidence of 18.7 per 100,000 population. However, the estimation of real incidence was much higher. The disease had an uncomplicated clinical course in most patients $(94.4 \%)$ and therefore many patients did not seek medical care. Not all patients who had sought the medical care underwent laboratory tests, and the virus was not successfully proven in all samples tested. Out of 1,014 cases, 131 (12.9 $\%)$ were hospitalized, of which 43 (4.2\%) required admission to an intensive care unit (ICU). Thirty-eight cases died (incidence: 0.7/100,000 population; case-fatality rate: $3.75 \%$ ).

In accordance with the results of other studies from France, USA and Netherlands $(6,7,8)$ and as opposed to seasonal influenza, most of the cases occurred in young and middle-aged adults. Highly affected was the youth group aged $15-24$ years. The proportion of $62.3 \%$ of all cases occurred in the age group of 15-44 years, while less than $1 \%$ of adults aged over 64 years were affected. Experts explain this by pre-existing immunity of persons born before $1957(8,9,11,12)$. When comparing the clinical course of the disease and its association to age, cases with severe outcome were significantly older (median age 35 years) than cases with non-severe outcome (median age 24 years). These observations are consistent with other studies from California, Australia and $\operatorname{UK}(10,11,12)$ The presence of these chronic underlying 
conditions can worsen the clinical course of influenza illness in both seasonal and pandemic types of influenza. Most of the deaths (97\%) occurred in cases aged less than 64 years, as described in UK $(12,13)$.

The symptoms recorded in the majority of cases, such as fever (84.8\%) and acute respiratory symptoms (84.3\%), as well as other symptoms (headache, arthralgia and myalgia) were not different from the classical picture of seasonal influenza $(7,15)$. Gastrointestinal symptoms reported elsewhere $(7,10,14,15)$ as being characteristic for the pandemic influenza infection were reported only in 37 (9.7\%) cases. Dyspnoe was reported in 47 cases and it may be explained by the later development of pneumonia or by the exacerbation of chronic underlying conditions like asthma, or COPD or cardiovascular disease.

The most commonly reported risk factors in our study, such as allergy $(5.4 \%)$, obesity $(4.5 \%)$, gravidity $(3.7 \%)$, pulmonary disease (3.5\%), asthma (2.2\%), and cardiovascular disease (2.1 $\%)$, are in line with the studies from other countries $(6,7,10)$.

As mentioned above, the clinical course of most Slovak patients $n=957(94.4 \%)$ was uncomplicated. This is consistent with the reports elsewhere $(16,17)$. A severe outcome was observed in $57(5.4 \%)$ cases while $75 \%$ of them were admitted to ICU; pneumonia developed in $51 \%$ of cases, and $67 \%$ of cases with severe outcome died.

In multivariate analysis, we found that COPD, cardiovascular disease, malignity and gravidity were independent risk factors for severe outcome of cases. COPD and cardiovascular disease are generally accepted risk factors for severe outcome of patients with pandemic and seasonal types of influenza (18). Unlike other countries, but in line with the data reported from Netherlands, obesity was not a risk factor for disease severity in Slovakia. Twelve pregnant women were included in our study group. In addition to pregnancy, they did not report any other risk factors and they have not been vaccinated against seasonal flu. Five of them were admitted to ICU and all 5 died.

In our study patients, the increase in number of risk factors was significantly associated with severe outcome of illness. However, 20 patients (35\%) with severe outcome had no risk factor, which in line with the results of a study carried out in France (6) points out that the pandemic influenza virus can cause a very serious disease even in humans without any risk factors. Median age of these patients was 30 years.

The study has several limitations. While at the beginning of the pandemic, all cases underwent laboratory tests and were reported, in the later stage only severe cases underwent laboratory tests and were reported. The major limitation of the study was data incompleteness. Due to this we could not analyze the effect of antiviral therapy on the disease course. For the same reason, we also did not analyze the data on complications (i.e. dehydration, development of ARDS) of the course of the disease. The data were collected only as to whether the patient required mechanical ventilation or oxygenotherapy. Thirty-five (61.4\%) out of 57 patients with severe outcome were treated with either mechanical ventilation or oxygenotherapy. Extracorporeal membrane oxygenation (ECMO) was not used in Slovakia.
Our study confirms the role of COPD, cardiovascular disease, malignity and gravidity as risk factors for severe outcome of cases with pandemic influenza. One third of young completely healthy adults developed severe illness. This indicates that the role of preventive public health measures such as vaccination is of importance.

\section{References}

1. Centers for Disease Control and Prevention (CDC). Outbreak of swine-origin influenza $\mathrm{A}(\mathrm{H} 1 \mathrm{~N} 1)$ virus infection - Mexico, March-April 2009. MMWR Morb Mortal Wkly Rep 2009; 58 (17): 467-470. Available from: http://www.cdc.gov/mmwr/preview/mmwrhtml/mm5817a5.htm

2. World Health Organization (WHO). Statement by WHO DirectorGeneral, Dr Margaret Chan on 25 April 2009. Available from http://www. who.int/mediacentre/news/statements/2009/h1n1_20090425/en/index.html

3. World Health Organization (WHO). Statement by WHO DirectorGeneral, Dr Margaret Chan on 11 June 2009. Available from: http://who.int/ mediacentre/news/statements/2009/h1n1_pandemic_phase6_20090611/en/ index.html

4. Úrad verejného zdravotníctva SR (ÚVZ SR). Výročná správa SR 2009. 2010. Available from: http://www.uvzsr.sk/index.php?option=com_conte nt\&view=article \&id=872:vyrona-sprava-za-rok-2009\&catid=25:vyronasprava\&Itemid $=34$

5. Summers JA, Wilson N, Baker MG. New research on pandemic influenza at the World Congress of Epidemiology, Edinburgh, 7-11 August 2011. Euro Surveill 2011; 16 (45): pii=20011. Available online: http://www. eurosurveillance.org/ViewArticle.aspx?ArticleId=20011

6. Fuhrman C, Bonmarin I, Paty AC, Duport N, Chiron E, Lucas E, Bitar D, Mailles A, Herida M, Vaux S, Lévy-Bruhl D. Severe hospitalised 2009 pandemic influenza A(H1N1) cases in France, 1 July-15 November 2009. Euro Surveill 2010; 15 (2): pii=19463. Available online: http://www. eurosurveillance.org/ViewArticle.aspx?ArticleId=19463

7. Jain S, Kamimoto L, Bramley AM, Schmitz AM, Benoit SR, Louie J et al. Hospitalised patients with $2009 \mathrm{H} 1 \mathrm{~N} 1$ influenza in the United States, April-June 2009. N Engl J Med 2009; 361 (20): 1925-1944.

8. van 't Klooster TM, Wielders CC, Donker T, Isken L, Meijer A, van den Wijngaard CC, van der Sande MA, van der Hoek W. Surveillance of Hospitalisations for 2009 Pandemic Influenza A(H1N1) in the Netherlands, 5 June - 31 December 2009. Euro Surveill 2010; 15 (2): pii=19461. Available online: http://www.eurosurveillance.org/ViewArticle.aspx?ArticleId=19461

9. Ikonen N, Strengell M, Kinnunen L, Österlund P, Pirhonen J, Broman M, Davidkin I, Ziegler T, Julkunen I. High frequency of crossreacting antibodies against 2009 pandemic influenza $\mathrm{A}(\mathrm{H} 1 \mathrm{~N} 1)$ virus among the elderly in Finland. Euro Surveill 2010; 15 (5) : pii=19478. Available online: http://www.eurosurveillance.org/ViewArticle.aspx? ArticleId $=19478$

10. Louie JK, Acosta M, Winter K, Jean C, Gavali S, Schechter R et al. Factors associated with death or hospitalization due to pandemic $2009 \mathrm{influ}-$ enza A(H1N1) infection in California. JAMA 2009; 302 (17): 1896-1902.

11. Citation style for this article: New South Wales public health network. Progression and impact of the first winter wave of the 2009 pandemic H1N1 influenza in New South Wales, Australia. Euro Surveill 2009; 14 (42) : pii=19365. Available online: http://www.eurosurveillance.org/ ViewArticle.aspx?ArticleId=19365 
12. Pebody RG, McLean E, Zhao H, Cleary P, Bracebridge S, Foster K, Charlett A, Hardelid P, Waight P, Ellis J, Bermingham A, Zambon M, Evans B, Salmon R, McMenamin J, Smyth B, Catchpole M, Watson JM. Pandemic Influenza A (H1N1) 2009 and mortality in the United Kingdom: risk factors for death, April 2009 to March 2010. Euro Surveill 2010; 15 (20): pii=19571. Available online: http://www.eurosurveillance. org/ViewArticle.aspx?ArticleId=19571

13. Donaldson LJ, Rutter PD, Ellis BM, Greaves FE, Mytton OT, Pebody RG et al. Mortality from pandemic A/H1N1 2009 influenza in England: public health surveillance study. BMJ 2009; 339: b5213.

14. European Centre for Disease Prevention and Control (ECDC). Risk Assessment - 2009 influenza A(H1N1) pandemic, Version 7. 2009. Available online: http://www.ecdc.europa.eu/en/healthtopics/Documents/0908_ Influenza_AH1N1_Risk_Assessment.pdf

15. World Health Organization (WHO). Clinical features of severe cases of pandemic influenza. 2009. Available online: http://www.who. int/csr/disease/swineflu/notes/h1n1_clinical features 20091016/ en/index.html

16. World Health Organization (WHO). Human infection with pandemic A (H1N1) 2009 influenza virus: clinical observations in hospitalized patients, Americas, July 2009 - update. WER 2009; 84 (30): 305-308.

17. Cao B, Li XW, Mao Y, Wang J, Lu HZ, Chen YS. Clinical features of the initial cases of 2009 pandemic influenza A (H1N1) virus infection in China. N Engl J Med 2009; 361 (26): 2507-2517.

18. Santa-Olalla Peralta P, Cortes-García M, Vicente-Herrero M, Castrillo-Villamandos C, Arias-Bohigas P, Pachon-del Amo I, Sierra-Moros MJ, on behalf of the Surveillance Group for New Influenza A(H1N1) Virus Investigation and Control Team in Spain. Risk factors for disease severity among hospitalised patients with 2009 pandemic influenza A (H1N1) in Spain, April - December 2009. Euro Surveill. 2010;15 (38):pii=19667. Available online: http://www.eurosurveillance.org

Received December 2, 2013. Accepted January 23, 2015. 